\title{
Idling Performance under Valve Deactivation Strategy in Port Fuel Injection Engine
}

\author{
A. S. Paimon' ${ }^{1}$, S. Rajoo ${ }^{2}$, W. Jazair ${ }^{1}$, M. A. Abas² and Z. H. Che Daud ${ }^{3}$ \\ ${ }^{1}$ Malaysia-Japanese International Institute of Technology, Universiti Teknologi \\ Malaysia, 54100, Kuala Lumpur, Malaysia \\ Email: solehinpaimon@gmail.com \\ Phone: +60133566240 \\ ${ }^{2}$ Centre for Low Carbon Transport In Cooperation with Imperial College London, \\ Universiti Teknologi Malaysia, 81310 Skudai, Johor, Malaysia \\ ${ }^{3}$ School of Mechanical Engineering, Universiti Teknologi Malaysia, \\ 81310 Skudai, Johor, Malaysia
}

\begin{abstract}
This paper investigates the effect of valve deactivation (VDA) on idling performance in port fuel injection (PFI) engine. The test was conducted on 1.6L, 4-cylinder engine with PFI configuration. One of the two intake valves in each cylinder was deactivated (zero lift on deactivated port) and fuel injector was modified to only provide fuel spray on the active intake port. In-cylinder pressure was recorded by the combustion analyzer in order to measure and analyze the combustion characteristics. From the test, there are up to $6 \%$ of fuel consumption improvements across all the test conditions. Better combustion stability is achieved at very low idling speed (throttle position, TP $=2 \%$ ) as a lower coefficient of variation of engine speed $\left(\mathrm{COV}_{\mathrm{rpm}}\right)$ and coefficient of variation indicated mean effective pressure $\left(\mathrm{COV}_{\text {imep }}\right)$ were recorded. Increased intake velocity and swirl flow in the VDA strategy creates more turbulence intensity causing higher heat release rate and faster combustion. However, there is no significant difference in the pumping work during the intake cycle but there is extra pumping work recorded towards the end of expansion stroke due to the very early end of combustion. Therefore, valve deactivation strategy provides limited positive improvement to the idling performance in PFI engine.
\end{abstract}

Keyword: Idling, reduced idle speed, VVA, valve deactivation, combustion stability.

\section{INTRODUCTION}

Heavy delays in traffic congestion due to rising numbers of car in urban areas have led to a significant increase in vehicle idling duration. In the current urban part of New European Drive Cycle (NEDC), idle operation represent $24 \%$ of the total driving time [1]. In real congested city driving situation, the idle proportion could be much higher especially in the area where more signalised intersection exists. Air pollution concentration from vehicle emission is high in congested signalized intersection due to longer vehicle idle in that area [2-6]. Increasing vehicle traffic in the signalized intersection during the red light will cause more fuel losses and exhaust emissions [7]. The rise of vehicle emissions caused by the congested traffic and increased vehicle number in the urban area causes unacceptable impact on human health and environment issues [8-11].

The engine idle is the condition where the engine is running while the vehicle is not in motion. The fuel consumed in idling is not converted into the energy to move the 
vehicle. The longer vehicle stays in idling, the more fuel is burned and wasted thus emits more total emission. Since engine idle is running at very low speed with almost no load, there are few issues involved such as highly rich combustion, high pumping losses, low combustion stability, slow combustion due to slow flow velocity and high rate of exhaust emission. The gasoline engine has comparatively higher fuel consumption and emission rate than equivalent diesel engine except for nitrogen oxide $\left(\mathrm{NO}_{\mathrm{x}}\right)$ and particulate matter (PM) during engine idle [12].

Variable valve actuation (VVA) strategy is a well-known technique to improve engine performance in part-load operation [13-16]. Low intake valve lift strategy provides high-velocity intake flow and turbulence at the valve gap in low engine load and speed [17] resulting in better combustion efficiency, combustion stability and significant improvement in pumping loss as reported by Kreuter et al. [18]. They also added that less than $2.1 \mathrm{~mm}$ of valve lift is needed to achieve the unthrottled operation under idling. Clenci et al. [19] combines low intake valve lift with late intake valve opening (LIVO) on port fuel injection engine (PFI) during idling; found that better mixture homogenisation is achieved by the increased turbulence due to high in-flow velocity. Also, reduced internal exhaust gas fraction (IEGR) and improved mixture quality from LIVO has resulted in higher heat release rate in idling speed. However, in PFI engine, low valve lift may cause a complex fuel break-up mechanism during the air-fuel interaction as discussed by Clenci et al. [19].

Valve deactivation (VDA) or single intake valve operation is another VVA strategy to improve part-load operation by generating higher intake flow velocity [20] and produce more swirl at low engine speed. Patel et al. [21] found similar effects of the valve deactivation in producing higher swirl index in gasoline direct injection (GDI) engine. High swirl improves burned residual dilution, results in higher burn rate and more stable combustion at low load [22]. Single intake valve operation with low lift $(2.1 \mathrm{~mm}$ max lift) at low load has contributed in decreasing indicated specific fuel consumption (ISFC) and engine out total hydrocarbon (THC), nitrogen oxide $\left(\mathrm{NO}_{\mathrm{x}}\right)$, and carbon monoxide (CO) [21]. Although intake VDA could only provide limited improvement to the pumping loss at low speed, it could still produce lower brake specific fuel consumption due to better in-cylinder mixing motion [20].

Lower idling speed may reduce fuel consumption due to lower engine revolution per time. However, the interval duration of valve overlap will increase and causing more time for the burned exhaust gas to re-enter the cylinder during the intake stroke. This results in more residual to mix with fresh intake charge. Combination of low turbulence due to slow intake velocity and high residual fraction in low idling speed create very poor mixture homogenization thus resulting in weak combustion and misfire. A richer air-fuel ratio is required to compensate the weak combustion into acceptable combustion stability level. Hence, more fuel is burned, and higher THC is emitted to the environment.

According to Heywood [23], partial burning which creates incomplete combustion and slow combustion due to bulk flame quenching is the source of higher HC concentrations. Increasing the fuel injection quantities will increase the THC concentrations during idle. The rate of $\mathrm{NO}_{\mathrm{x}}$ formation is proportional and dependent on the burned gas temperature [23-25]. Lower exhaust gas temperature resulted from lower combustion temperature would potentially reduce $\mathrm{NO}_{\mathrm{x}}$ emission to the environment [26].

Although gasoline direct injection (GDI) engine has higher efficiency and better performance than port fuel injection (PFI) engines, studies to improve PFI performance are still relevant due to its lower cost and wide usage in economic vehicles worldwide. Since there are only a few studies were focusing on improving idling performance on port 
fuel engine (PFI) using VVA strategy instead of low intake valve lift, this paper aims to investigate the effect of valve deactivation (VDA) operation in idling performance under regular and reduced idling speed using PFI configuration.

A 1.6L 4-cylinder SI engine (4 valves per cylinder) with PFI configuration was tested on the base and VDA strategy in idling speed. In VDA strategy, one of the two intake valves on each cylinder are closed and having no lift during the run while the other intake valve operates in full lift. Fuel consumption and combustion characteristics for different idling speed were analysed and compared to the base strategy.

\section{EXPERIMENTAL METHOD}

A study was carried out to investigate the effect of valve deactivation on the low idling speed performance. The test was performed on a 1.6L 4-cylinder engine with two intake valves and two exhaust valves per cylinder (see Table 1 for engine specification). The engine is equipped with independent engine control unit (ECU) to manage the ignition timing and fuel injection pulse width and timing. A Bosch LSU 4.2 wideband lambda sensor is placed at the exhaust collector before the catalytic converter to measure the airfuel ratio.

The in-cylinder pressure measurement unit for combustion analysis is consist of Dewetron combustion analyzer (DEWE-5000-CA2-PROF), a high-temperature pressure sensor (Kistler Type $6052 \mathrm{C} ; \leq \pm 2 \%$ of sensitivity) and a crank angle encoder (Kistler type $2613 \mathrm{~b}$; crank angle signal resolution: $0.4^{\circ} \mathrm{CA}$, dynamic accuracy: $\leq \pm 0.02^{\circ} \mathrm{CA}$ ). The incylinder pressure sensor is installed on the first cylinder and crank angle encoder is attached on the crankshaft pulley through an adapter. Both crank angle encoder and pressure sensor are connected to the Dewetron combustion analyzer and 300 consecutive cycles are taken as sample for each test condition.

Table 1. Test engine specification.

\begin{tabular}{ll}
\hline Parameters & Description \\
\hline Type & Multi-port fuel injection \\
Displacement & $1597 \mathrm{cc}$ \\
Bore x stroke & $76 \mathrm{~mm} \times 88 \mathrm{~mm}$ \\
Compression ratio & 10 \\
Intake valve & Dia. $30 \mathrm{~mm} ; \max$ lift $8.7 \mathrm{~mm}$ \\
Exhaust valve & Dia. $25 \mathrm{~mm}$ max lift $8.35 \mathrm{~mm}$ \\
Throttle body & Dia. $45 \mathrm{~mm}$ \\
\hline
\end{tabular}

One of the two intake valves on each cylinder was deactivated by removing the shim bucket in order to maintain zero lift on the affected valves as there is no contact between the cam lobe and valve stem as shown in Figure 1. Intake valve timing for both base and VDA cases remained as original. Six-hole port fuel injectors were used for the test; three holes for each port in every cylinder. Three injector holes were blocked on the deactivated valve port to prevent the fuel from being resided in the deactivated intake port during the intake process. Standard unleaded RON 95 fuel was used for the test. The fuel flow rate was measured using high precision volumetric type fuel flow detector (ONO SOKKI PF 2240HA; accuracy $< \pm 0.2 \%$ ). The air-fuel ratio was maintained at stoichiometric (lambda, $\lambda=1$ ) at all test conditions. Engine coolant temperature was kept $\leq 85^{\circ} \mathrm{C}$ during the test. The schematic diagram of the experimental setup is shown in Figure 2. 


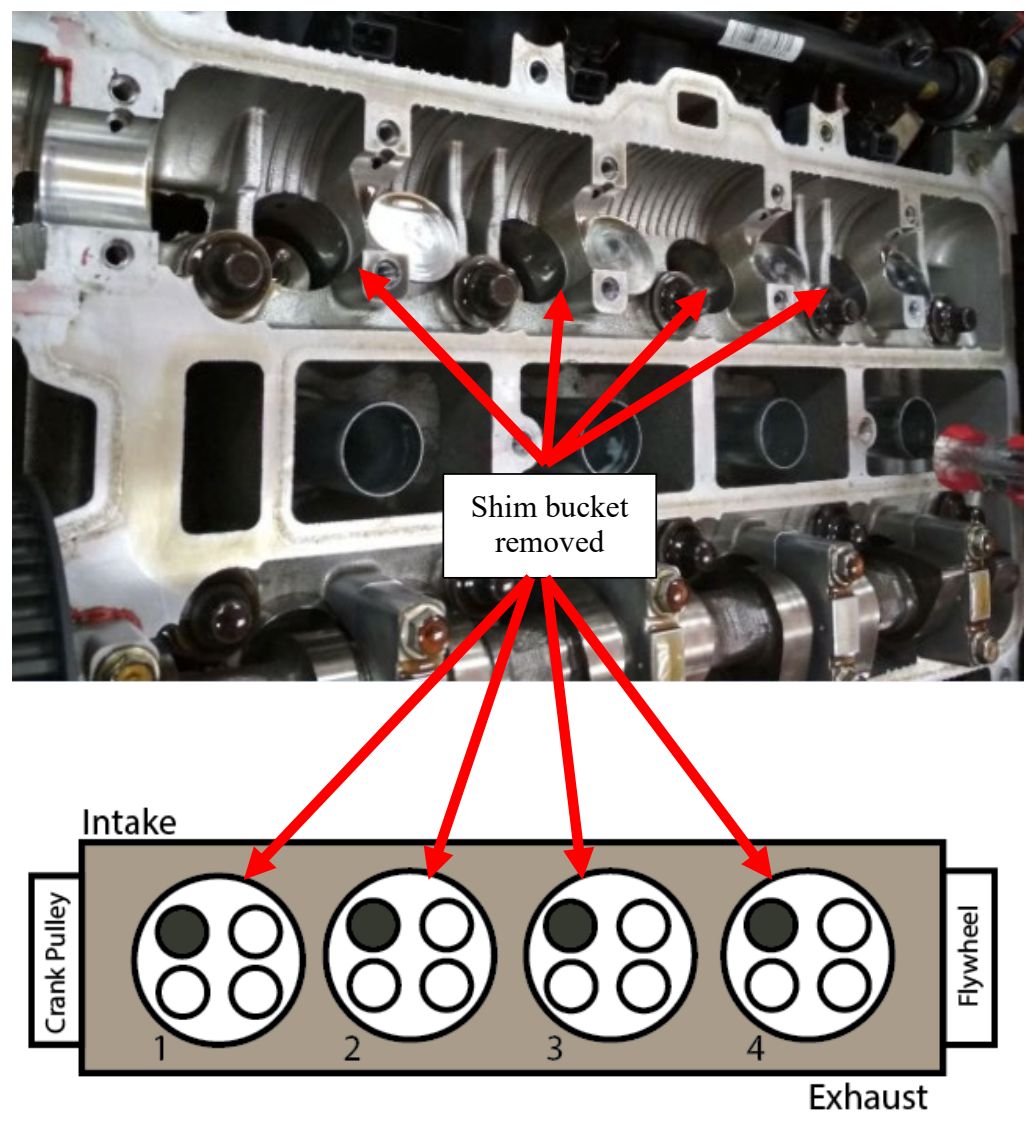

Figure 1. Valve train setup for VDA strategy.

A mechanical throttle body with manual control was used for the test. All bypass flow on the throttle body was blocked to avoid any external flow other than through throttle plate since the experiment methodology uses throttle opening as a reference. Ignition advance (IA) was fixed at $25^{\circ}$ before top dead centre (BTDC). Achieving similar engine speed with fixed IA in idling is difficult since it requires a very small increment of throttle opening which is not possible in this case. Therefore, throttle opening was used as a reference in this test in comparing the performances for both the cases.

\section{RESULTS \& DISCUSSION}

\section{Fuel Consumption}

Figure 3(a) shows the engine idling speed in each throttle position respectively for base and VDA mode. It can be seen that VDA strategy has higher engine speed at each throttle opening position (TP) compared to the base mode. The ignition advance (IA) before TDC for both the base and VDA strategy were fixed at $\mathrm{IA}=25^{\circ}$ in order to eliminate the effect of ignition timing on the combustion characteristics. Due to no-load under idling condition and fixed ignition timing, it is difficult to get similar engine speed at similar TP for both the cases. It can be seen in Figure $2 b$ that at similar TP, VDA obtained lower manifold absolute pressure indicating higher flow velocity as a result of greater pressure difference across the intake manifold. This is possibly one of the reasons for higher idling speed in VDA in each TP than that of the base configuration. Hence, in order to compare 
the amount of fuel used on different engine idling speed, fuel-injected quantity per cycle $(\mathrm{mg})$ in each cylinder was used to evaluate the fuel consumption fairly.

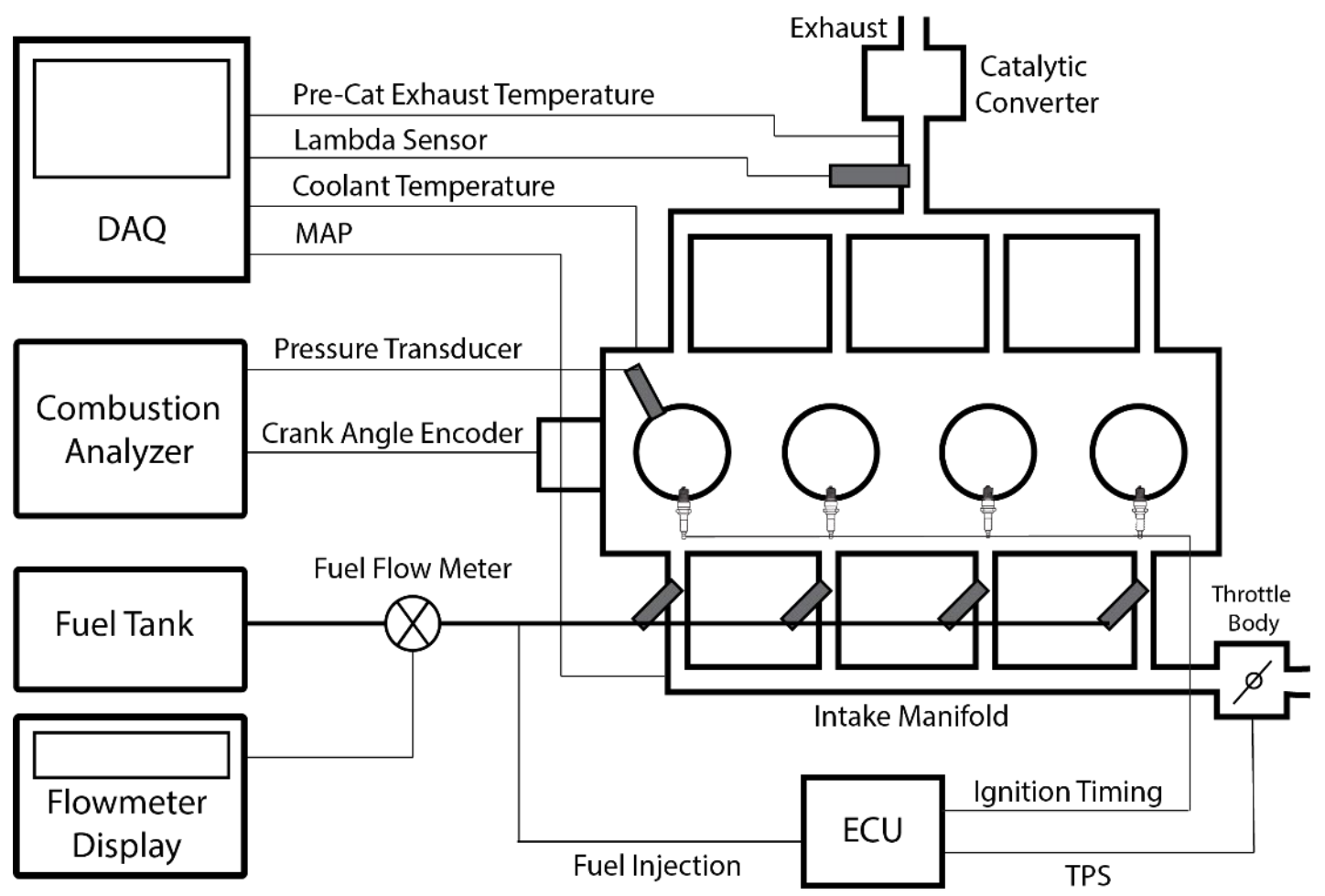

Figure 2. Experimental test rig schematic diagram.

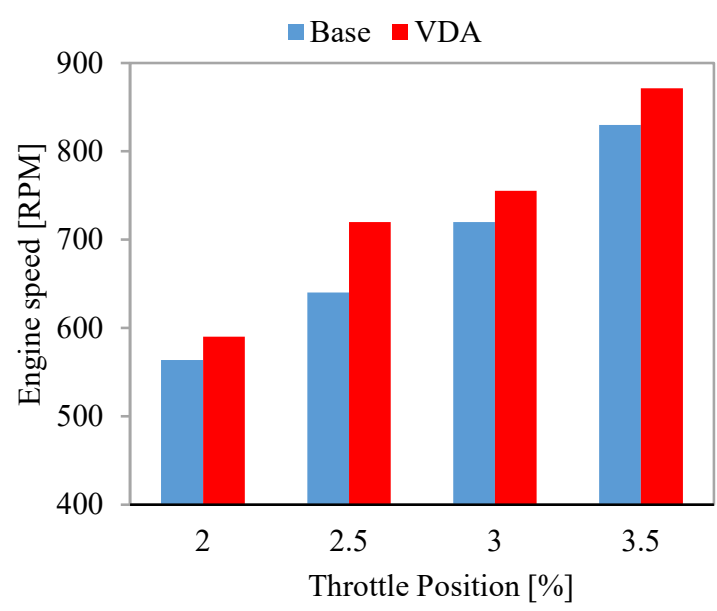

(a)

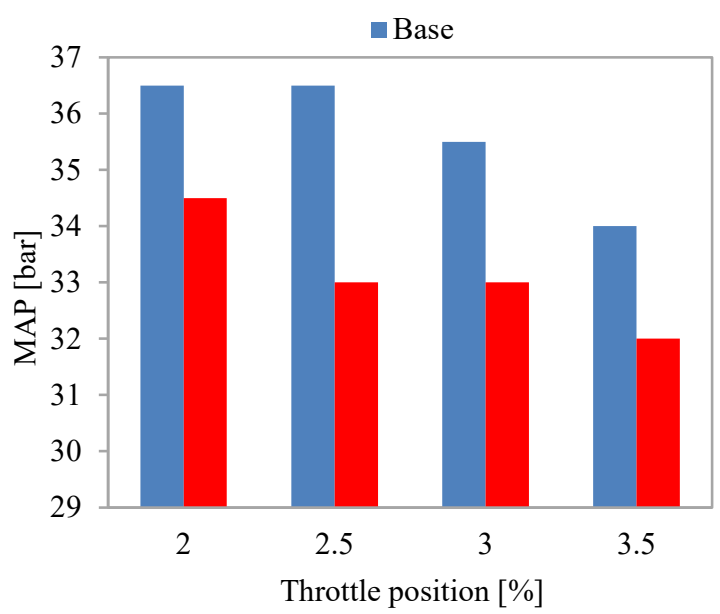

(b)

Figure 3. (a) Engine speed vs. throttle position and (b) manifold absolute pressure vs. throttle position.

In Figure 4, at TP $=2 \%$; the amount of fuel injected for the base is $5.812 \mathrm{mg}$ for idling speed of $560 \mathrm{rpm}$ which is almost similar to VDA's $5.808 \mathrm{mg}$ at the higher idling speed of $590 \mathrm{rpm}$. VDA strategy records a lower amount of fuel injected of $5.705 \mathrm{mg}$ at $720 \mathrm{rpm}$ than the base $(6.131 \mathrm{mg})$ running at $640 \mathrm{rpm}$ for $\mathrm{TP}=2.5 \%$. As for $\mathrm{TP}=3 \%$ and 
$3.5 \%$, VDA strategy shows $6.84 \%$ and $3.76 \%$ lower amount of fuel injected respectively compared to the base even though both the VDA cases were running at higher idling speed than the base. If the amount of fuel were to compare directly for similar idling speed regardless of TP, it is found that VDA strategy still shows $6.03 \%$ of improvement in fuel consumption at $720 \mathrm{rpm}$ where TP is $2.5 \%$ for VDA and $3 \%$ for base as seen in Figure 3(a) and Figure 4.

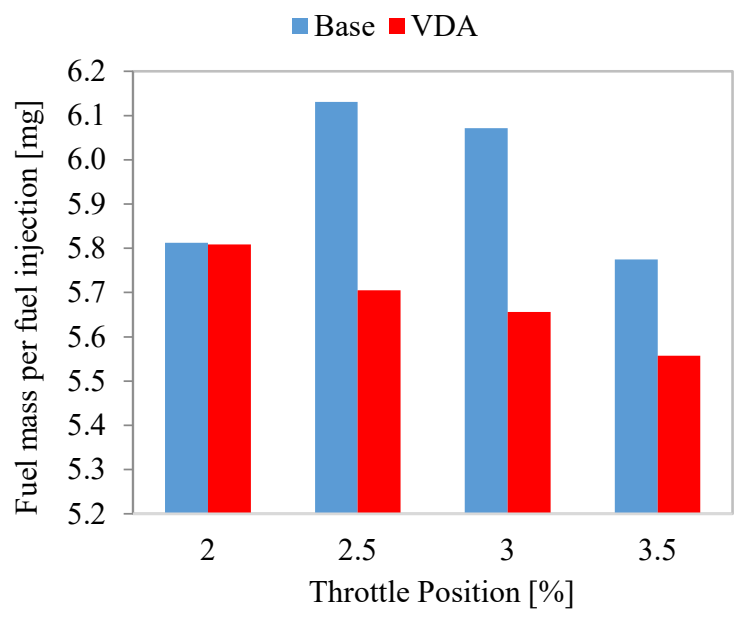

Figure 4. Fuel consumption.

\section{Combustion Characteristic}

Combustion stability is one of the key parameters to be concerned in order to improve fuel economy and emission. Pressure-related and engine speed parameters are often used to quantify the combustion stability. In this study, the coefficient of variation of indicated mean effective pressure $\left(\mathrm{COV}_{\text {imep }}\right)$ and engine speed $\left(\mathrm{COV}_{\mathrm{rpm}}\right)$ are evaluated to indicate engine cyclic variation. $\mathrm{COV}$ is referred to as Eq. (1) [23]:

$C O V_{x}=\left[\sigma_{x} / \bar{x}\right] \times 100 \%$

Where $x$ represents the value of IMEP $(\mathrm{kPa})$ or engine speed $(\mathrm{rpm}), \bar{x}$ represent the average value and $\sigma_{x}$ is the standard deviation of respective parameters. The COV value is expressed in percentage.

Figure 5 shows the $\mathrm{COV}_{\text {imep }}$ against different throttle opening (TP) in idling speed. VDA strategy shows lower percentage of $\mathrm{COV}_{\text {imep }}$ at each TP except for higher TP at $3.5 \%$ compared to base strategy. The combustion stability degradation becomes more apparent as the TP and engine speed decreased. At lowest TP or lowest idling speed, VDA strategy shows the most significant reduction in cyclic variation of IMEP. However, the $\mathrm{COV}_{\text {imep }}$ seems to increase as the TP goes higher for VDA while the fluctuation of IMEP for the base mode remains at the same level from TP $2.5 \%$ to $3.5 \%$.

Figure 6 shows the coefficient of variation of engine speed $\left(\mathrm{COV}_{\mathrm{rpm}}\right)$ at each TP. VDA strategy shows better idling speed stability where most significant reduction occurred at TP $2 \%$ and $3 \%$. Since only one valve is opened instead of two valves in VDA strategy during intake stroke, the flow area for the intake charge to flow into the cylinder has been reduced to half from the original. The reduced flow area results in higher intake flow velocity into the cylinder as all the intake charge were forced into the single valve 
opening when the piston moving downward. In addition, less amount of exhaust residual from the single intake valve opening is suspected to contribute in lower fluctuation in IMEP and idling speed resulting in more complete combustion. At very low idle speed, chances of more fuel scavenged from intake to exhaust are higher in normal engine configuration as the time duration of valve overlap is longer, probably resulting in high total hydrocarbon (THC).

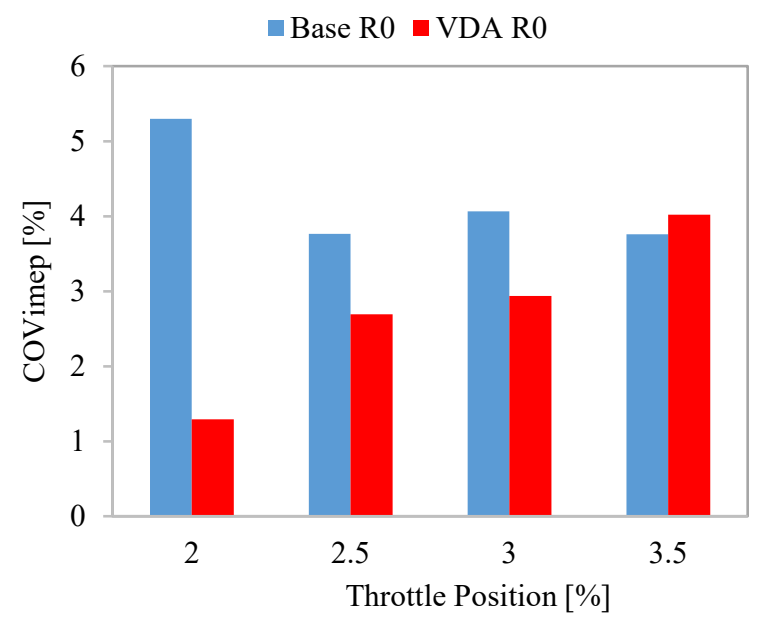

Figure 5. COV of IMEP.

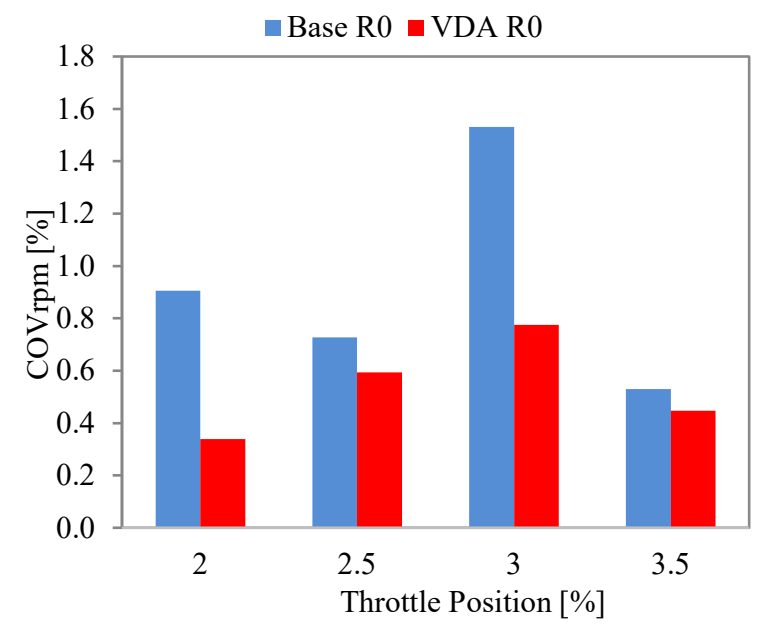

Figure 6. COV of RPM.

Figure 7 presents the average 300 cycle in-cylinder pressure trace for the base and VDA strategies at lowest $\mathrm{TP}=2 \%$ and $\mathrm{IA}=25^{\circ}$. VDA strategies show $36.7 \%$ higher peak pressure and steeper slope of pressure rise. Higher heat release rate produced by VDA as in Figure 8 is the possible reason for greater peak pressure during the combustion. At the lowest idling speed, the slower piston downward movement pumping the intake charge results in slower velocity of intake flow and generates lower turbulences. This results in poor mixing of air-fuel mixture and causing poor combustion. Increased intake flow velocity in the single valve application generates more turbulence flow and improved mixture homogenization. Reduced exhaust gas residual during the intake stroke with 
VDA also contribute to creating more quality on the combustion as a result of better intake mixture quality in low idle speed.

The use of valve deactivation is to create swirl flow as there is almost no swirl produced in a twin symmetrical intake valve due to the balanced nature of the port design. Additionally, the highest swirl index obtained is when one valve having full lift while the other valve with less than $1 \mathrm{~mm}$ lift. Swirl flow is generally applied in spark-ignition engine to create faster combustion process due to higher dilution tolerance with the burned residual as mentioned by Grover et al. [27]. Valve deactivation (VDA) combines the high-velocity swirl and tumble flow to generates high turbulence flow which enhances the mixture homogenization resulting higher tolerance to residual gas especially during low speed and idle speed. The first law of thermodynamics is applied in the heat release rate calculation with the following assumptions;

i. Working fluid follow ideal gas properties.

ii. No heat loss through heat transfer.

iii. Constant mass of cylinder gas.

iv. Crevice and piston blow-by effects are neglected.

Thus, the amount of net heat release rate (HRR) can be defined as Eq. (2) [23,28].

$$
\frac{d Q(\theta)}{d \theta}=\left(\frac{1}{k-1}\right) V(\theta) \frac{d P(\theta)}{d \theta}+\left(\frac{k}{k-1}\right) P(\theta) \frac{d V(\theta)}{d \theta}
$$

where $P$ is in-cylinder pressure and $V$ is cylinder volume corresponds to the crank angle $(\theta)$ position. $k$ is specific heat ratio and crank angle $(\theta)$ is in degree.

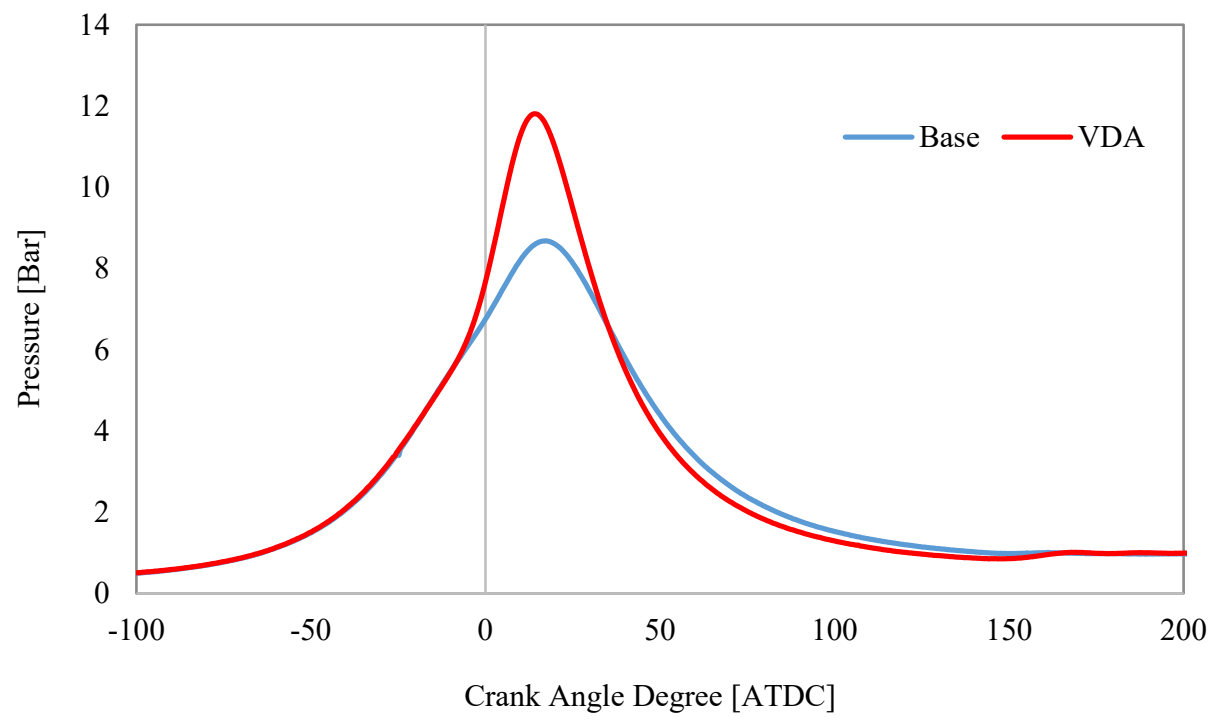

Figure 7. In-cylinder pressure trace.

In Figure 8, VDA strategy indicates higher heat release rate as compared to base strategy at $\mathrm{TP}=2 \%$. Ignition advance (IA) is $25^{\circ} \mathrm{BTDC}$ for both the cases. Almost similar Start of Combustion (SOC) were recorded by VDA and base cases but the end of combustion (EOC) for VDA is at 32.0 CAD which is 37.2 CAD earlier than the base case. EOC was determined by which crank angle degree (CAD) where the value of heat release rate reaches the first zero after the combustion. Faster combustion in VDA is a result of 
better mixture homogenization and the ability to dilute residual gases to form higher combustion quality.

Mass fraction burned (MFB) is often used to describe the chemical energy release of the internal combustion engine as a function of crank angle. In this case, Rassweiler and Withrow method is used for MFB calculation as shown in Eq. (3) where $\Delta p_{c}$ is the pressure rise from the combustion, $\theta$ is crank angle and $N$ is the total number of crank angle interval.

$M F B=\frac{m_{b, \theta}}{m_{b, t o t a l}}=\frac{\sum_{1}^{\theta} \Delta p_{c}}{\sum_{l}^{N} \Delta p_{c}}$

MFB5 (5\% of mass fraction burned) or the flame development process is the crank angle duration from the point of spark discharge in which small fraction or 5\% of mass in cylinder is burned. This early stage of combustion is very crucial because the initial flame kernel is very sensitive to the mixture motion and composition around the spark plug. The mass fraction burned curves are plotted in Figure 9. VDA strategy shows faster flame development process (MFB5 $=-3.1 \mathrm{CAD}$ ) as compared to base (MFB5 =0.6 CAD). In the flame propagation process (MFB5-90), shorter combustion duration was recorded for VDA (MFB5-90 = 20.8 CAD) which is half of the interval required by the base to end the of propagation stage.

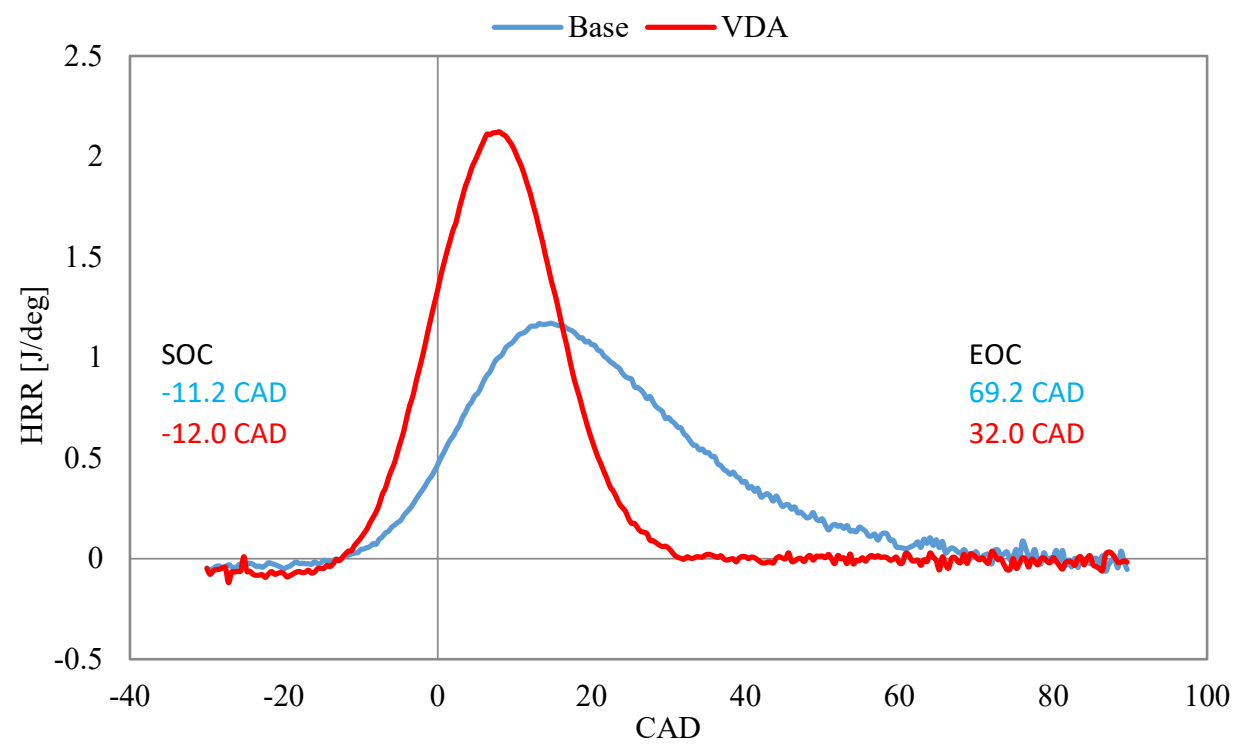

Figure 8. Heat release rate.

There is significant variability or the coefficient of variation of MFB5 (COVMFB5) for base strategy as seen in Figure 10. It is possibly because of the large fraction of gas residual exists in the intake mixture due to longer valve overlap duration in the low idle speed. Lower dilution tolerance due to lower turbulence flow creates poor mixture during the early flame development process thus increases the variability of MFB5. In the case of VDA, higher turbulence from swirl and tumble flow by the valve deactivation produced higher tolerance to the residual gas dilution resulting in lower COVMBF5. Also, it is believed that lower fraction of exhaust residual during the valve overlap may contribute to low variability of MFB5 since the effective flow area on the intake is 
reduced due to only one intake valve is opened during the intake stroke. Hence, cyclic variability of MFB5 is suspected to contribute to the cyclic variability of IMEP, RPM and $P_{\text {Max. }}$

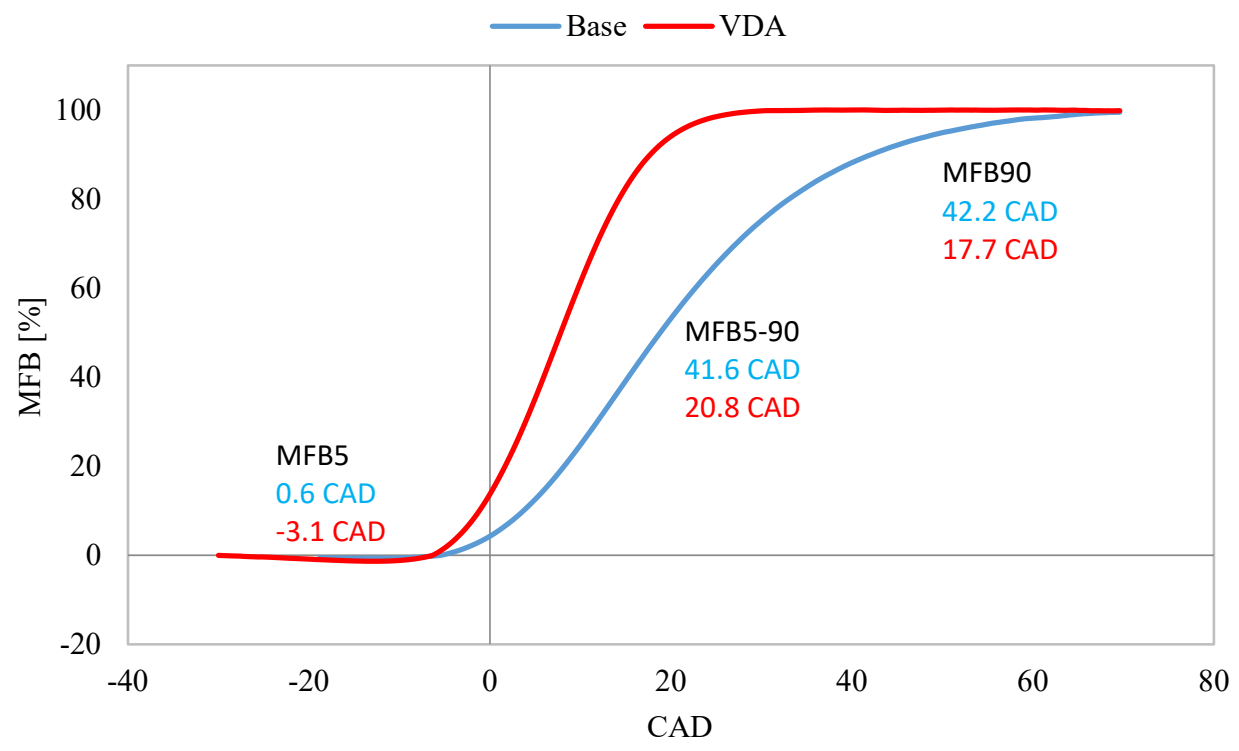

Figure 9. Mass fraction burned.

In Figure 12, we can see the scattered data of maximum in-cylinder pressure ( $\left.\mathrm{P}_{\mathrm{Max}}\right)$ and indicated mean effective pressure (IMEP) for 300 consecutive cycles. It can be seen that VDA has lower cyclic variability of IMEP and $\mathrm{P}_{\text {Max. This is a result of lower }}$ cyclic variability of MFB5 during the early combustion phase. Average IMEP for VDA is 1.81 bar which is $4 \%$ lower than the base case as seen in Figure 11. In-cylinder pressure trace diagram (Figure 7) shows pressure drop is very fast after the peak pressure and it is crossing below the base cylinder pressure during the expansion. High heat release rate in the VDA case (Figure 8) causing very early EOC (at 32 CAD) thus resulting pressure to drop faster and dropping below the base cylinder pressure after 35.6 CAD (combustion in base still occurring until 69.2 CAD). As a consequence, the average IMEP is lower because of the rapid pressure fall during the early expansion process.

The higher average maximum pressure obtained by VDA as seen in Figure 7 can be possibly regarded to the cumulative effects of the events as follow:

i. Higher heat release rate at the TDC area (Figure 8) where the cylinder volume is very small would create enormous amount of pressure inside the cylinder.

ii. High mean velocity and turbulences of the global mixture during the flame propagation process. The indication of global mixture motion can be seen in the cyclic variability of MFB50 in Figure 11 where in VDA, COV MFF50 $_{\text {is }}$ higher than that of base.

Normally, swirl flow generated during the intake stroke will decay due to friction through compression, combustion and expansion process as mentioned by Heywood [23]. However, in this case, it is believed that high turbulence flow from the high swirl and tumble flow generated by the valve deactivation does not entirely decay as it went towards the end of compression stroke. 


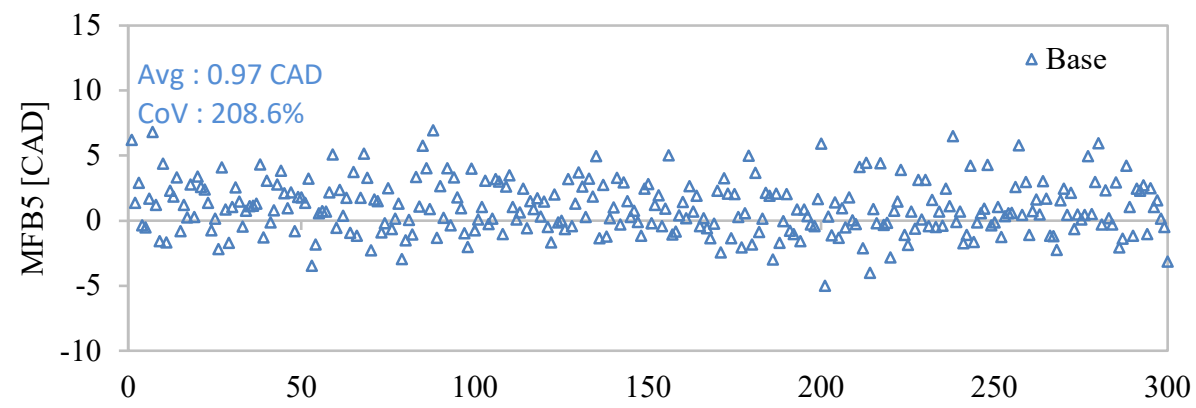

(a)

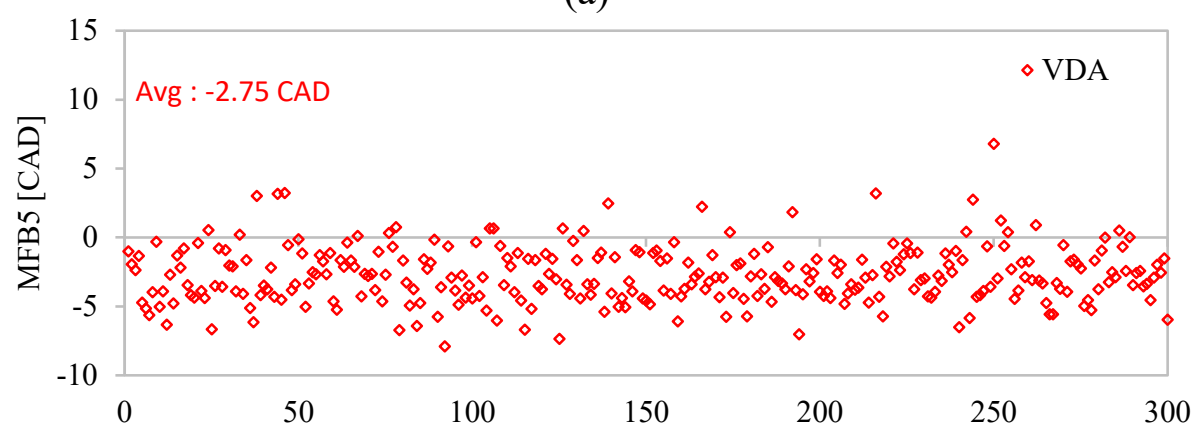

(b)

Figure 10. MFB5.

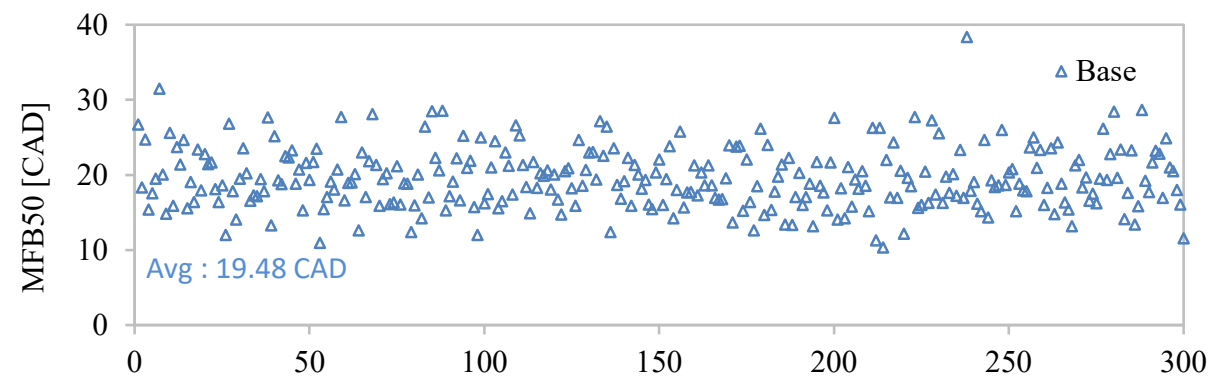

(a)

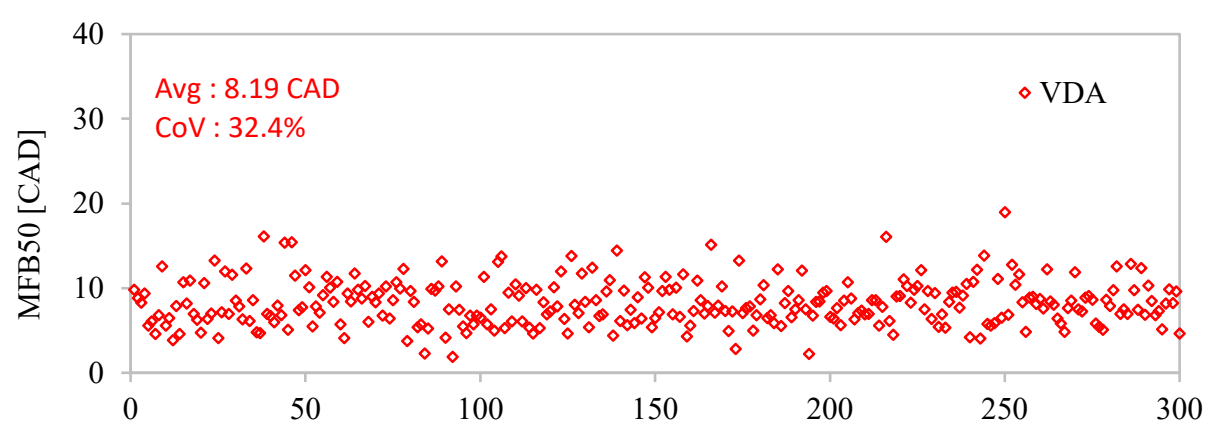

(b)

Figure 11. MFB50. 


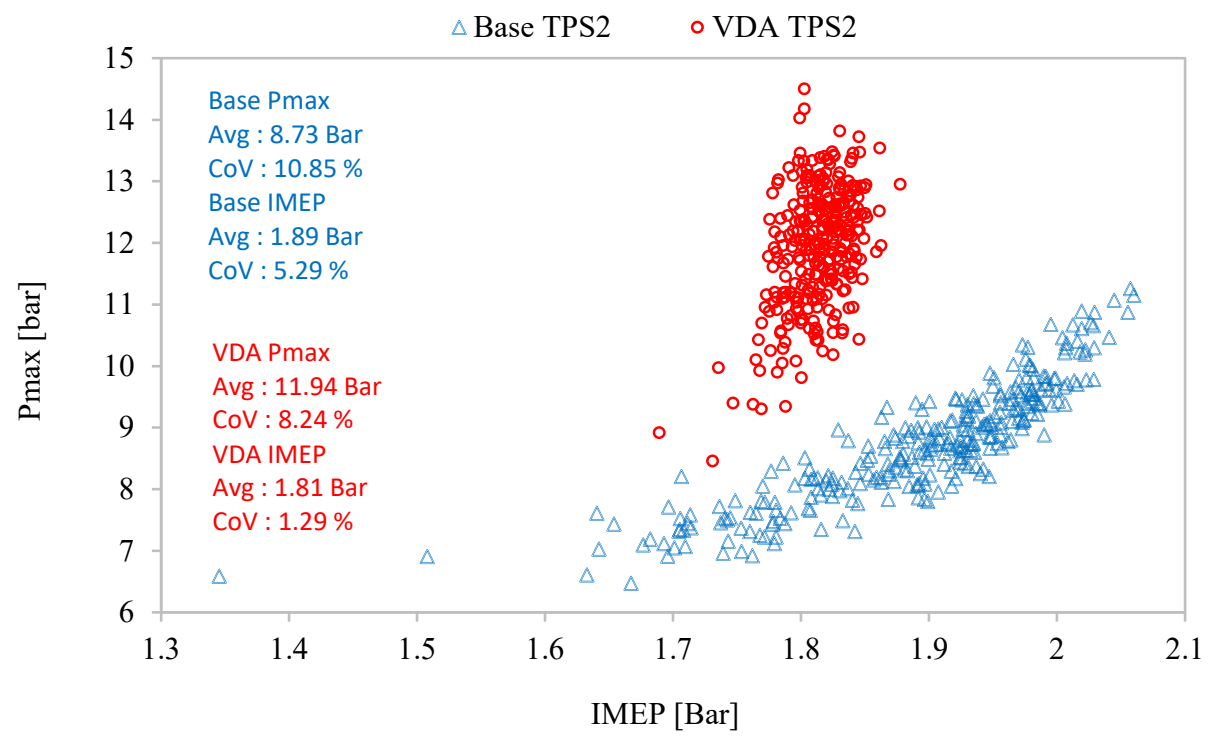

Figure 12. PMax vs IMEP.

Figure 13(a) shows pumping work done by the piston. Area A is known as unrecovered pumping work or defined as a net-work required during the gas exchange process which is the network that is lost during the intake stroke. As can be seen, there is no significant difference in pumping work between both the cases during the intake process (area A). This shows that in idling speed, single intake valve strategy with full lift still operates under throttled condition thus causing no improvement to the pumping loss. However, unthrottled operation and lower pumping loss could be achieved by introducing lower valve lift with appropriate valve timing [21]. Towards the end of expansion stroke; VDA shows significant negative loop (area B in Figure 13(a)) resulting in higher total pumping mean effective pressure (PMEP $=0.714$ bar) as compared to the base case $(\mathrm{PMEP}=0.694)$.

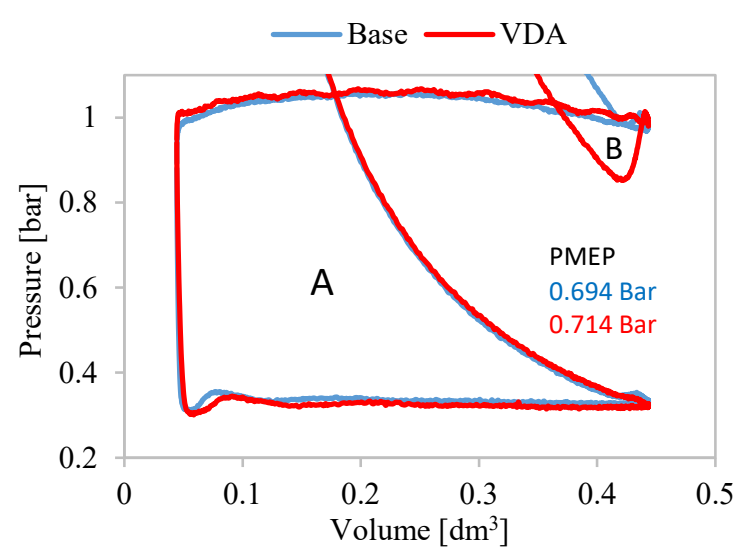

(a)

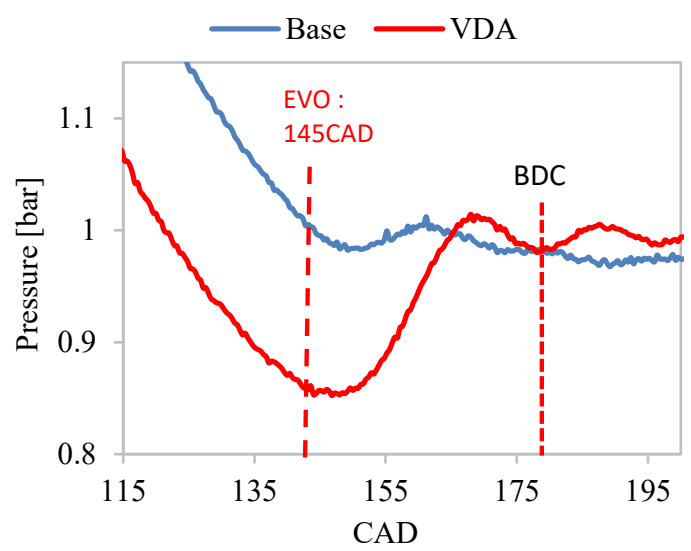

(b)

Figure 13. (a) Pumping loop and (b) in-cylinder pressure during the end of expansion and early exhaust stroke.

Rapid pressure falls after the early EOC during the expansion process (see Figure 7) is causing the cylinder pressure to fall below atmospheric before exhaust valve opening (EVO: 149 CAD) creating vacuum or extra pumping work as seen in Figure 13(b). 
Therefore, greater pumping work in VDA strategy is mainly caused by the extra pumping work done during the expansion process.

\section{Emission}

Figure 14 presents the exhaust temperature for the respective throttle opening (TP) in idle speed for both the base and VDA strategies. The temperature was taken at the exhaust collector before the catalytic converter. From the observation, combustion in VDA strategy during idle speed produces lower exhaust gas temperature (between $9 \%$ to $12 \%$ of reduction) at all four TP. This indicates that combustion temperature was lesser in VDA.

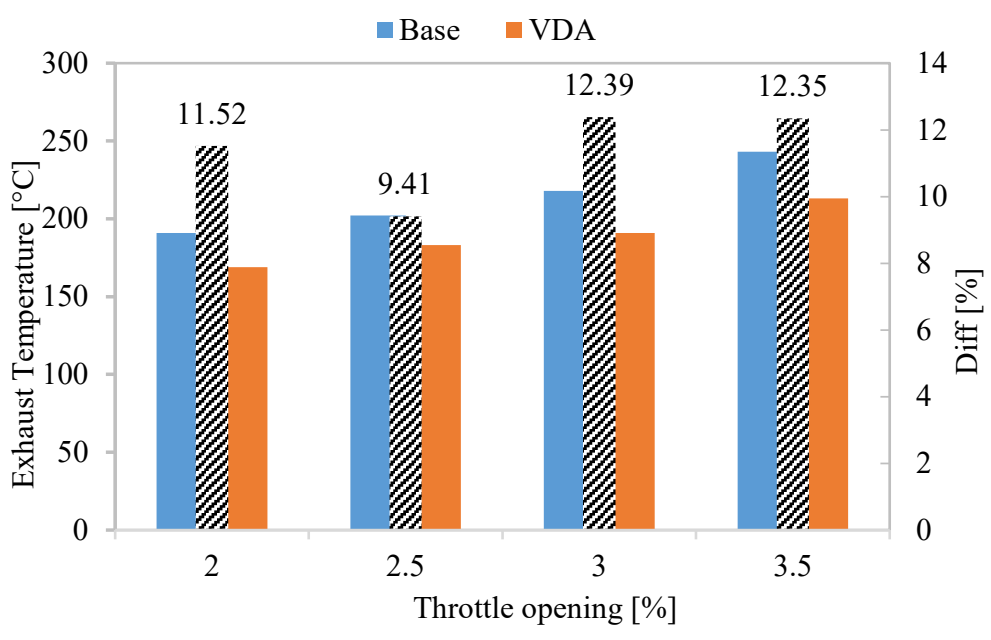

Figure 14. Exhaust temperature.

Due to the absence of reliable emission analyzer, no emission results are presented in this paper. However, there are some comments on the emission for VDA strategy can be made based on the fundamental theory and other research findings:

i. $\quad$ VDA is believed to have lower nitrogen oxide $\left(\mathrm{NO}_{\mathrm{x}}\right)$ emission due to the fact that the rate of $\mathrm{NO}_{\mathrm{x}}$ formation is proportional to the burned gas temperature as stated by Heywood [23].

ii. VDA is expected to have lower total hydrocarbon emission (THC) since it has better combustion quality or more complete combustion shown by its fast and high combustion stability. Also, lower fuel injection quantities as presented in Figure 4 would contribute to reducing the THC emission.

However, proper emission measurement on the VDA application in idle speed needs to be conducted in order to support the hypothesis made above.

\section{CONCLUSION}

This experimental study is conducted to investigate the effect of intake valve deactivation (VDA) strategy on idling performance. From the results presented earlier, the following conclusions could be made on the application of VDA in idling:

i. VDA strategy during idling has higher intake flow velocity due to lower intake manifold absolute pressure (MAP) and higher engine speed in similar throttle opening. 
ii. There are $3 \%$ to $6 \%$ of improvement on the fuel consumption at all throttle opening conditions using VDA except at TP $2 \%$.

iii. Better combustion stability at very low idling speed is obtained with VDA strategy as lower cyclic variability of IMEP and idling engine speed (RPM) were recorded.

iv. VDA creates faster combustion and higher heat release rate due to higher intake flow velocity and turbulence at very low idling speed.

v. Higher total PMEP work was found in VDA strategy as there was extra pumping work towards the end of expansion stroke due to very early end of combustion.

vi. Lower exhaust gas temperature in VDA is expected to produce lower $\mathrm{NO}_{\mathrm{x}}$ emission although the total amount of $\mathrm{NO}_{\mathrm{x}}$ is already low during idling.

\section{REFERENCES}

[1] Marotta A, Pavlovic J, Ciuffo B, Serra S, Fontaras G. Gaseous Emissions from Light-Duty Vehicles: Moving from NEDC to the new WLTP test procedure. Environmental Science \& Technology 2015; 49(14): 8315-8322.

[2] Xu J, Hilker N, Turchet M, Al-Rijleh M-K, Tu R, Wang A, et al. Contrasting the direct use of data from traffic radars and video-cameras with traffic simulation in the estimation of road emissions and PM hotspot analysis. Transportation Research Part D: Transport and Environment 2018; 62: 90-101.

[3] Goel A, Kumar P. A review of fundamental drivers governing the emissions, dispersion and exposure to vehicle-emitted nanoparticles at signalised traffic intersections. Atmospheric Environment 2014; 97: 316-331.

[4] Kwak K-H, Woo S, Kim KH, Lee S-B, Bae G-N, Ma Y-I, et al. on-road air quality associated with traffic composition and street-canyon ventilation: mobile monitoring and CFD modeling. Atmosphere 2018; 9(3): 92.

[5] Thaker P, Gokhale S. The impact of traffic-flow patterns on air quality in urban street canyons. Environmental Pollution 2015; 208: 1-9.

[6] Lin C, Gong B, Qu X. Low emissions and delay optimization for an isolated signalized intersection based on vehicular trajectories. PLOS ONE Public Library of Science 2016; 10(12): 1-17.

[7] Sharma N, Kumar PP, Dhyani R, Ravisekhar C, Ravinder K. Idling fuel consumption and emissions of air pollutants at selected signalized intersections in Delhi. Journal of Cleaner Production 2019; 212: 8-21.

[8] Mohamad ND, Ash'aari ZH, Othman M. Preliminary assessment of air pollutant sources identification at selected monitoring stations in Klang Valley, Malaysia. Procedia Environmental Sciences 2015; 30: 121-126.

[9] Chen X, Shao S, Tian Z, Xie Z, Yin P. Impacts of air pollution and its spatial spillover effect on public health based on China's big data sample. Journal of Cleaner Production 2017; 142: 915-925.

[10] Othman J, Sahani M, Mahmud M, Sheikh Ahmad MK. Transboundary smoke haze pollution in Malaysia: Inpatient health impacts and economic valuation. Environmental Pollution 2014; 189: 194-201.

[11] World Health Organization. Ambient (outdoor) air quality and health. Retrieved from https://www.who.int/en/news-room/fact-sheets/detail/ambient-(outdoor)air-quality-and-health; 22 May, 2019.

[12] Shancita I, Masjuki HH, Kalam MA, Fattah IMR, Rashed MM, Rashedul HK. A review on idling reduction strategies to improve fuel economy and reduce exhaust emissions of transport vehicles. Energy Conversion and Management 2014; 88: 
794-807.

[13] Pournazeri M, Khajepour A. Precise lift control in a new variable valve actuation system using discrete-time sliding mode control. Mechanism and Machine Theory 2016; 99: 217-235.

[14] Pournazeri M, Khajepour A, Huang Y. Improving energy efficiency and robustness of a novel variable valve actuation system for engines. Mechatronics 2018; 50: 121-133.

[15] Li Y, Khajepour A, Devaud C, Liu K. Power and fuel economy optimizations of gasoline engines using hydraulic variable valve actuation system. Applied Energy 2017; 206: 577-593.

[16] Teodosio L, Pirrello D, Berni F, De Bellis V, Lanzafame R, D’Adamo A. Impact of intake valve strategies on fuel consumption and knock tendency of a spark ignition engine. Applied Energy 2018; 216: 91-104.

[17] Xu J, Chang S, Fan X, Fan A. Effects of electromagnetic intake valve train on gasoline engine intake charging. Applied Thermal Engineering 2016; 96: 708-715.

[18] Kreuter P, Heuser P, Reinicke-Murmann J, Erz R, Peter U, Böcker O. Variable valve actuation - switchable and continuously variable valve lifts. SAE Technical Paper: 2003-01-0026; 2003.

[19] Clenci AC, Iorga-Simăn V, Deligant M, Podevin P, Descombes G, Niculescu R. A CFD (computational fluid dynamics) study on the effects of operating an engine with low intake valve lift at idle corresponding speed. Energy 2014; 71: 202-217.

[20] Binbin S, Song G, Bo L. Research of the intake valve deactivation on engine performance. International Journal of Engineering 2016; 29(4): 473-481.

[21] Patel R, Ladommatos N, Stansfield PA, Wigley G, Garner CP, Pitcher G, et al. Comparison between unthrottled, single and two-valve induction strategies utilising direct gasoline injection: emissions, heat-release and fuel consumption analysis. SAE Technical Paper: 2008-06-23; 2008.

[22] Zhang K, Chang Y, Xie Z, Sun T, Chen F. Effect of intake swirl on combustion performance in an unthrottled spark ignition engine. Proceedings of the Institution of Mechanical Engineers, Part D. Journal of Automobile Engineering 2019; 233(5): 1269-1279.

[23] Heywood JB. Internal Combustion Engine Fundementals. McGrawHill series in Mechanical Engineering; 1988.

[24] Rashid A, Mansor MRA, Aizon WG, Harun Z, Wan WMF. An experimental study of the performance and emissions of spark ignition gasoline engine. International Journal of Automotive and Mechanical Engineering 2016; 13: 3540-3554.

[25] Albayrak Çeper B, Yıldız M, Akansu SO, Kahraman N. Performance and emission characteristics of an IC engine under SI, SI-CAI and CAI combustion modes. Energy 2017; 136: 72-79.

[26] Ling CH, Abas MA. One-Dimensional simulation using port water injection for a spark ignition engine. International Journal of Automotive and Mechanical Engineering 2018; 15(4): 5803-5814.

[27] Grover OR, Chang J, Masters E, M. Najt P, Singh A. The effect of intake valve deactivation on lean stratified charge combustion at an idling condition of a sparkignition direct-injection (SIDI) Engine. Journal of Engineering for Gas Turbines and Power 2011; 134(9).

[28] Vipavanich C, Chuepeng S, Skullong S. Heat release analysis and thermal efficiency of a single cylinder diesel dual fuel engine with gasoline port injection. Case Studies in Thermal Engineering 2018; 12: 143-148. 